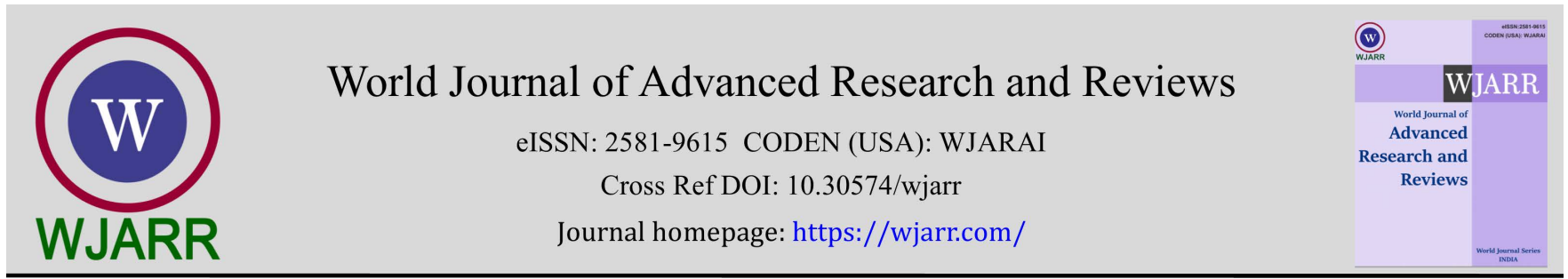

(RESEARCH ARTICLE)

Check for updates

\title{
Descriptive analysis of methadone 2021 participants before and after participating in the video editing workshop
} \author{
Sulistyawati ${ }^{2, *}$ \\ ${ }^{1}$ Faculty of Medicine, Universitas Airlangga, Indonesia. \\ ${ }^{2}$ Department of Parasitology, Faculty of Medicine, Universitas Airlangga, Indonesia.
}

Jonathan Christopher Wewengkang ${ }^{1}$, Gokmalina Clementin Odile ${ }^{1}$, Intan Alda Safira ${ }^{1}$ and Sri Wijayanti

World Journal of Advanced Research and Reviews, 2022, 13(01), 487-494

Publication history: Received on 08 December 2021; revised on 10 January 2022; accepted on 12 January 2022

Article DOI: https://doi.org/10.30574/wjarr.2022.13.1.0039

\begin{abstract}
Since the enactment of the Indonesian Government regulation, namely Pemberlakuan Pembatasan Kegiatan Masyarakat (PPKM), many community activities have to be carried out from home. It is undeniable that the presence of negative and positive emotions in the young generation of productive age during this pandemic have an impact on their creativity. They are more open to new creative ideas. In addition, the feeling of boredom facing this pandemic can also be reduced by doing creative activities, one of which is video editing. One way to increase creativity in video editing is found through skills training and in this case, the group of 8 KKN FK UNAIR held an online workshop in the METHADONE event series as a platform that facilitates basic training in video editing. This study was conducted with the aim of knowing the description of the character, knowledge, and behavior of participants before and after participating in the METHADONE 2021 video editing workshop. The research design chosen was descriptive analysis using primary data based on the results of pre-test and post-test questionnaires whose validity had been tested using correlation value (Pearson Correlation) and reliability test with Cronbach's Alpha method. Samples were taken using Total Sampling technique that met the research inclusion criteria. Then, the data were analyzed using SPSS software and presented descriptively with a frequency distribution table. Most participants were women aged 17-25 years old. This study shows that this workshop provided has an effect and improves the participants' understanding and ability in editing videos.
\end{abstract}

Keywords: Video editing; Productivity; Pandemic; Workshop

\section{Introduction}

The COVID-19 Pandemic started in Indonesia in March 2020 and has affected multiple aspects of human life. These include economy, health, social, culture, education, tourism, and so much more. The government has conducted much effort to reduce the infection rate of COVID-19, one of which is Large-Scale Social Restrictions or known as Pembatasan Sosial Berskala Besar (PSBB), which later turned into Enforcement of Restrictions on Community Activities or known as Pemberlakuan Pembatasan Kegiatan Masyarakat (PPKM). A couple of policies established during the PPKM from the 3rd to the 25th of July 2021 include online learning and the obligation for non-essential sector workers to $100 \%$ work from home [1]. Working and learning from home brought a lot of positive and negative effects. The positive effects include (i) reduced travel time, and transportation cost; (ii) workers can organize their work schedule and environment; (iii) balanced work-life [2]; (iv) learning activities can be practical, quick, and relaxed; (v) acquire new experiences [3]; (vi) increased productivity and creativity [4]. On the other hand, a couple of adverse effects includes (i) difficulty in adapting and coordinating with coworkers; (ii) unclear working time limit, which tends to lead to limitless working time

\footnotetext{
${ }^{*}$ Corresponding author: Sri Wijayanti Sulistyawati

Department of Parasitology, Faculty of Medicine, Universitas Airlangga, Indonesia.

Copyright $(2022$ Author(s) retain the copyright of this article. This article is published under the terms of the Creative Commons Attribution Liscense 4.0.
} 
[2]; (iii) limited facilities and connections; (iv) high cost of internet data; (v) reduced understanding of learning materials; (vi) reduced motivation to follow online learning activities [3].

People in the productive age group are arguably the most affected by the pandemic. The massive amount of time spent at home, to some even losing their jobs, forced them to unlock their potential, one of which is through increasing their creativity [5]. Many methods can be used to increase one's creativity, including experimenting with new things, doing research, being involved in real-life action, and training specific skills. According to David Campbell, creativity can create results that feel new, innovative, never before seen, exciting, eccentric, and valuable for the general public [6]. Developing creativity has positive effects, from personal happiness to creating a new work environment. The development of and the inseparable connection of the younger generation to technology has allowed the creative economy to develop rapidly [7]. The emergence of a creative economy is evidence that with a vast outlook along with high motivation, the younger generation has a chance to move the economic sector, including times of pand emic such as this one. According to Antariksa in Handayani [7], there are fifteen sub-sectors in a creative economy which include architecture, design, film, video, and photography, culinary arts, artisan goods, fashion, music, publishing and printing, interactive, commercial, research, arts, drama, IT, television, as well as radio.

One's creativity could be an adaptive response towards hardships, including the ongoing pandemic [8]. A negative mood during the pandemic could make a person more critical and intelligent, producing creative and valuable ideas. The presence of positive and negative emotions during the pandemic affects creativity. When someone feels happy and sad simultaneously, they are more open to new and creative perspectives and thoughts. To remove the feeling of boredom, many people create a strategy to lighten their moods. Creative activities are one of the sources of satisfaction in fighting boredom felt during the pandemic [9]. A creative activity that is quite interesting is video editing. The ability to edit videos has garnered some attention in the current day and age, starting with the reasons of hobby, work, to school work that must be submitted in the form of a video. Both students in school and universities are expected to have the essential ability to edit a video. Other than that, many social media users usually induce interest in millennials to create exciting content either in a photo or video. Video editing has also become an attractive business opportunity due to its promising market. Businesses that started as a hobby are starting to gain public interest. Almost every activity nowadays requires the media to remember that moment, one of which is in the form of a video. Other than the chance of the business starting from a hobby, a video editing business is also simple; the work can be done anywhere, including at home, the skills necessary can be learned from anywhere, and the income produced is also promising [10]. In this age of a pandemic, one could learn and add to their skills from anywhere, including an online workshop. After changing all activities into online activities, various instances begin conducting online seminars that are either free or require a fee, making it easier to obtain new knowledge from various fields, wherever and whenever one might be.

The abundance of online-based seminars, as well as the high demand for learning new things during the current pandemic era, causes the 8th KKN group from the COVID module of the Medicine Faculty of Universitas Airlangga to be interested in including a workshop that discusses the basic skills in video editing in the activities of METHADONE. This activity aims to provide a chance to learn video editing to increase productivity in this current pandemic era. The participants are expected to gain knowledge, from video-taking techniques to editing and adding transitions and background audio. Then, the group will also give pre-test and post-test questionnaires to determine the effects of the workshop. From the results of the questionnaires, the group will research the participants' changes of character, knowledge, and behavior before and after participating in the METHADONE 2021 video editing workshop.

\section{Material and methods}

The chosen research design is descriptive analysis using primary data based on the results of the questionnaire which are pre-test and post-test of METHADONE 2021 video editing workshop. The sample is taken with the total sampling technique which fits in the inclusion criteria of the research, which are participants of METHADONE 2021 video editing workshop within the ages 12 - 35 years old, and has filled both pre-test and post-test given during the workshop. This research will be done online by spreading the pre-test and post-test links through the Zoom Meeting from the $9^{\text {th }}$ to the $19^{\text {th }}$ of July 2021. The data collected will then be analyzed descriptively and shown in the form of a frequency distribution table.

To measure the validity of the questionnaire, the Product Moment Correlation Formula from Pearson is used. The validity test is done using SPSS software. The instrument is determined to be valid if the Pearson Correlation value is positive and the Correlation Probability value [sig. (2-tailed)] is less than the significance level of $0,01$.

From the table, it is found that the result of the Correlation Probability Value [sig. (2-tailed)] of each question is less than 0,01 , therefore the questions listed in the questionnaire are valid. 


\begin{tabular}{|l|c|c|}
\hline Item & Sig. (2-tailed) & Criteria \\
\hline Desc1PRE & 0.000 & VALID \\
\hline Desc3PRE & 0.000 & VALID \\
\hline Desc4PRE & 0.000 & VALID \\
\hline Desc5PRE & 0.000 & VALID \\
\hline totaldescPRE & 0.000 & VALID \\
\hline
\end{tabular}

To measure the questionnaire reliability, Cronbach's Alpha method is used. The reliability test is done using SPSS software. If the results found by using Cronbach's Alpha method is more than 0,90, then the reliability of the questionnaire is perfect. If the results found by using Cronbach's Alpha method is between $0,70-0,90$, then the reliability of the questionnaire is high. If the results found by using Cronbach's Alpha method is between 0,50-0,70, then the reliability of the questionnaire is moderate. If the results found by using Cronbach's Alpha method is less than 0,50 , then the reliability of the questionnaire is low.

\begin{tabular}{|c|c|}
\hline Cronbach's Alpha & N of Items \\
\hline 0,814 & 5 \\
\hline
\end{tabular}

From the table above, it is found that in the Reliability Statistics section the Cronbach's Alpha value is equal to 0,814. This proves that the questionnaire is highly reliable.

\section{Results and discussion}

\subsection{Participant Age Distribution}

Table 1 Participant Age Distribution

\begin{tabular}{|l|c|c|}
\hline Age Group & Frequency & Percentage (\%) \\
\hline $12-16$ years old & 199 & 21.4 \\
\hline $17-25$ years old & 716 & 77.0 \\
\hline $26-35$ years old & 15 & 1.6 \\
\hline Total & 930 & 100 \\
\hline
\end{tabular}

Table 1. shows the distribution of the age of the participants that participated in METHADONE video editing workshop. From this table, it is known that the late adolescents age group (17-25 years old) has the highest number of participants which are 716 (77\%) participants. On the other hand the early adulthood age group (26-35 years old) has the lowest number of participants which are $15(1,6 \%)$ participants. This could be explained by the curiosity of the late adolescents age group. The presence of curiosity makes and motivates a person to want to continue learning and developing. Curiosity is also needed by everyone to increase their skills. For example, in a late adolescent's life, curiosity will motivate them into developing their own potential. Also, curiosity is needed to sustain themselves when entering the workforce [11].

\subsection{Gender Distribution of Participants}

Table 2. shows the sex distribution of participants who attended the METHADONE workshop. From the table, it is known that most of the participants who attended the workshop were women, as many as 851 (91.5\%) participants. Creative thinking skills trigger someone to do creative activities, one example is video editing. A study shows that gender has no effect on a person's creative thinking skills. However, there are also studies which say that there is a significant difference where women have higher creative thinking skills than men [12]. 
Table 2 Gender Distribution of Participants

\begin{tabular}{|l|c|c|}
\hline Gender & Frequency & Percentage (\%) \\
\hline Male & 79 & 8.5 \\
\hline Female & 851 & 91.5 \\
\hline Total & 930 & 100 \\
\hline
\end{tabular}

\subsection{Differences in Participants' Pre-test and Post-test Scores}

Table 3 Participants' Pre-Test Score

\begin{tabular}{|l|c|c|}
\hline Pre-test & Frequency (n) & Percentage (\%) \\
\hline 0 & 282 & 30.3 \\
\hline 1 & 338 & 36.3 \\
\hline 2 & 156 & 16.8 \\
\hline 3 & 93 & 10.0 \\
\hline 4 & 34 & 3.7 \\
\hline 5 & 27 & 2.9 \\
\hline Total & 930 & 100 \\
\hline
\end{tabular}

Table 3. shows the participants' Pre-Test scores, namely before participating in the METHADONE workshop. From the table, it is known that the score "1" is the most common score obtained by the participants, namely 338 (36.3\%) participants, while the score " 5 " or correctly answering all questions is the least common score obtained by participants, which is 27 ( $2.9 \%$ ) of participants.

Table 4 Participants' Post-Test Score

\begin{tabular}{|c|c|c|}
\hline Pre-test & Frequency (n) & Percentage (\%) \\
\hline 0 & 165 & 17.7 \\
\hline 1 & 177 & 19.0 \\
\hline 2 & 154 & 16.6 \\
\hline 3 & 142 & 15.3 \\
\hline 4 & 130 & 14.0 \\
\hline 5 & 162 & 17.4 \\
\hline Total & 930 & 100 \\
\hline
\end{tabular}

Table 4. shows the participants' Post-Test scores, namely after attending the METHADONE workshop. From the table, it is known that the value "1" is still the most common score obtained by participants, namely 177 (19\%) participants. However, this shows that there is an increase in participants' knowledge about basic video editing after attending the METHADONE workshop because the number of participants who scored " 0 " and " 1 " has decreased compared to the Pre-Test data before attending the workshop. Then, the number of participants who scored " 4 " became the least number of participants, namely 130 (14\%) participants.

\subsection{Habits of participants in video editing}

Table 5. shows the participants' habits in editing videos. The level of habit of the METHADONE workshop participants in editing videos was written in the range of " 1 " (never) to "5" (very often). Participants who answered "4" (often edit videos) became the largest group that attended the workshop, namely 232 (24.9\%) participants, while participants who answered "1" (never edited videos) became the smallest group that took part in the workshop, namely as many as 7 $(0.8 \%)$ participants. The data shows that almost all workshop participants have edited videos before. 
Table 5 Habits of participants in video editing

\begin{tabular}{|l|c|c|}
\hline & Frequency (n) & Percentage (\%) \\
\hline 1 & 7 & 0.8 \\
\hline 2 & 34 & 3.7 \\
\hline 3 & 141 & 15.2 \\
\hline 4 & 232 & 24.9 \\
\hline 5 & 516 & 55.5 \\
\hline Total & 930 & 100 \\
\hline
\end{tabular}

\subsection{Tools used by participants to edit videos}

Table 6 Tools used by participants to edit videos

\begin{tabular}{|l|c|c|}
\hline Device & Frequency (n) & Percentage (\%) \\
\hline HP & 890 & 95.7 \\
\hline Laptop & 228 & 24.5 \\
\hline Others & 9 & 1.0 \\
\hline \multicolumn{2}{|c|}{${ }^{*}$ One participant can use $>1$ tool to edit video }
\end{tabular}

Table 6 shows the distribution of tools used by METHADONE video editing workshop participants to edit videos. From the table, the results show that participants who use cellphones to edit videos are the largest group that attends the workshop, namely 890 (95.7\%) participants, while there are only $9(1.0 \%)$ participants who use other tools. such as Computers/PCs and iPads. In this section each participant can use more than one tool to edit the video.

\subsection{Participants' desire to learn how to edit videos}

Table 7 Participants' desire to learn how to edit videos before the workshop

\begin{tabular}{|c|c|c|}
\hline & Frequency (n) & Percentage (\%) \\
\hline 1 & 8 & 0.9 \\
\hline 2 & 41 & 4.4 \\
\hline 3 & 199 & 21.4 \\
\hline 4 & 314 & 33.8 \\
\hline 5 & 368 & 39.6 \\
\hline Total & 930 & 100 \\
\hline
\end{tabular}

Table 7 shows the distribution of the level of participants' desire to learn video editing before getting the METHADONE video editing workshop. The level of participants' desire to learn to edit videos before getting to the workshop was measured by a number ranging from " 1 " (very unwilling) to " 5 " (very wanting). From the table above, it is found that most participants really want to learn video editing, as shown by as many as 368 (39.6\%) participants answered "5", while only $8(0.9 \%)$ participants answered " 1 " which means the participants are unwilling to learn to edit videos before attending the workshop.

Table 8 shows the distribution of participants' level of desire to learn video editing after receiving the METHADONE video editing workshop. The level of participants' desire to learn to edit videos after receiving the workshop was measured with a number ranging from " 1 " (very unwilling) to " 5 " (very wanting). From the table above, it was found that most participants really wanted to learn to edit videos, as shown by as many as 529 (56.9\%) participants answered 
"5" and there were no participants who answered "1" (very unwilling to edit videos). This shows that the basic video editing workshop provided can increase the participants' desire to learn video editing.

Table 8 Participant's desire to learn how to edit videos after the workshop

\begin{tabular}{|c|c|c|}
\hline & Frequency (n) & Percentage (\%) \\
\hline 1 & 0 & 0 \\
\hline 2 & 9 & 1.0 \\
\hline 3 & 98 & 10.5 \\
\hline 4 & 294 & 31.6 \\
\hline 5 & 529 & 56.9 \\
\hline Total & 930 & 100 \\
\hline
\end{tabular}

\subsection{Participants' understanding of how to edit videos}

Table 9 Participants' understanding of how to edit videos before getting a workshop

\begin{tabular}{|c|c|c|}
\hline & Frequency (n) & Percentage (\%) \\
\hline 1 & 25 & 2.7 \\
\hline 2 & 158 & 17.0 \\
\hline 3 & 394 & 42.4 \\
\hline 4 & 222 & 23.9 \\
\hline 5 & 131 & 14.1 \\
\hline Total & 930 & 100 \\
\hline
\end{tabular}

Table 9 shows the distribution of participants' level of understanding on how to edit videos before getting the METHADONE video editing workshop. The level of participants' understanding of how to edit videos before getting to the workshop was measured by a number ranging from " 1 " (very clueless) to " 5 " (very understanding). From the table above, it was found that most of the workshop participants, as many as $394(42.4 \%)$ participants answered with "3" which means they have little understanding of how to edit videos. A small number of participants, namely as many as $25(2.7 \%)$ participants did not really understand how to edit videos before attending the workshop.

Table 10 Participants' understanding of how to edit videos after receiving the workshop

\begin{tabular}{|c|c|c|}
\hline & Frequency (n) & Percentage (\%) \\
\hline 1 & 1 & 0.1 \\
\hline 2 & 11 & 1.2 \\
\hline 3 & 138 & 14.8 \\
\hline 4 & 357 & 38.4 \\
\hline 5 & 423 & 45.5 \\
\hline Total & 930 & 100 \\
\hline
\end{tabular}

Table 10 shows the distribution of participants' level of understanding on how to edit videos after receiving the METHADONE video editing workshop. The level of participants' understanding of how to edit videos after receiving the workshop was measured from the number " 1 " (very clueless) to " 5 " (very understanding). From the table above, the 
results show that most of the participants really understand how to edit videos, as evidenced by as many as 423 (45.5\%) participants answering " 5 ", while only $1(0.1 \%)$ participants answered with "1" which means they are still really don't know how to edit videos. This shows that the participants' understanding of how to edit videos increased after getting a basic video editing workshop.

\subsection{Ability of participants to edit videos before getting a workshop}

Table 11 Ability of participants to edit videos before getting a workshop

\begin{tabular}{|c|c|c|}
\hline & Frequency (n) & Precentage (\%) \\
\hline 1 & 23 & 2.5 \\
\hline 2 & 117 & 12.6 \\
\hline 3 & 372 & 40.0 \\
\hline 4 & 280 & 30.1 \\
\hline 5 & 138 & 14.8 \\
\hline Total & 930 & 100 \\
\hline
\end{tabular}

Table 11 shows the distribution of the level of participants' ability to edit videos before getting The METHADONE video editing workshop. The level of participants' ability to edit videos before getting to the workshop was measured with a number ranging from "1" (very poor) to " 5 " (very capable). From the table above, it was found that most of the workshop participants were slightly able to edit videos, as shown by as many as 372 (40\%) participants answered "3". A small number of participants, namely as many as 23 (2.5\%) participants felt that they were very incapable of editing videos before attending the workshop.

Table 12 Ability of participants to edit videos after getting the workshop

\begin{tabular}{|c|c|c|}
\hline & Frequency (n) & Precentage (\%) \\
\hline 1 & 1 & 0.1 \\
\hline 2 & 8 & 0.9 \\
\hline 3 & 163 & 17.5 \\
\hline 4 & 387 & 41.6 \\
\hline 5 & 371 & 39.9 \\
\hline Total & 930 & 100 \\
\hline
\end{tabular}

Table 12 shows the distribution of participants' ability levels to edit videos after receiving the METHADONE video editing workshop. The level of participants' ability to edit videos after receiving the workshop was measured with a number ranging from "1" (very poor) to " 5 " (very capable). From the table, it was found that most of the participants were quite capable of editing videos, as evidenced by as many as 387 (41.6\%) participants answered "4", while only 1 $(0.1 \%)$ participant answered with "1" which means he still felt very incapable to edit video. This shows that the basic video editing workshop provided improves the participants' ability to edit videos.

\section{Conclusion}

Based on the results of this study, the following conclusions are obtained regarding the description of the character, knowledge, and behavior of participants before and after participating in The METHADONE 2021 video editing workshop. From 930 workshop participants, the largest group of participants was found in the 17-25 year age group as many as 715 (77\%) participants. Almost all workshop participants were women with a total of 851 (91.5\%) participants. From the results of the pre-test and post-test questionnaires given, it was found that the participants' knowledge of basic video editing increased after attending the workshop. Most of the participants have edited videos before, with the most widely used tool being the mobile phone. This study also found that there were increase in the level of participants' desire to learn video editing, the level of understanding on how to edit videos, and their ability to 
edit videos after getting the METHADONE basic video editing workshop. This shows that the basic METHADONE video editing workshop provided has an effect and improves the participants' understanding and ability in editing videos. Hopefully, some event of this kind of workshop can be created and followed to increase any productivity skills during this COVID-19 pandemic.

\section{Compliance with ethical standards}

\section{Acknowledgments}

The authors wish to thank the Faculty of Medicine of Universitas Airlangga for their support in METHADONE's success, METHADONE's committee for their help in running the event and collecting data, Jefferson Ivan as the speaker in METHADONE's video editing workshop, as well as doctor Sri Wijayanti for her guidance.

\section{Disclosure of conflict of interest}

The authors declare that they have no conflicting interests.

\section{Statement of informed consent}

Informed consent was obtained from all individual participants included in the study.

\section{References}

[1] Idris M. PPKM is the abbreviation for Enforcement of Activity Restrictions[Internet]. Kompas.com. 2021.

[2] Mungkasa O. Working from Home (WFH): Towards a New Order in the Pandemic Era COVID 19. Jurnal Perencanaan Pembangunan: The Indonesian Journal of Development Planning. 2020; 4(2): 126-50.

[3] Adi NNS, Oka DN, Wati NMS. Positive and Negative Impacts of Distance Learning in a Pandemic Period COVID-19. Jurnal Imiah Pendidikan dan Pembelajaran. 2021; 5(1): 43-8.

[4] Simarmata RM. The Effect of Work From Home on the Productivity of Ambon State Polytechnic Lecturers. Intelektiva: Jurnal Ekonomi, Sosial, dan Humaniora. 2020; 2(01): 73-82.

[5] Bilqisthy AL, Zhafirah MN. Increasing Human Resources Creativity in the Midst of a Pandemic for Millennial Generation. National Conference of Administrative Science. 2020; 4(1): 43-8.

[6] Hurlock EB. Child Development, translated by Meitasari Tjandrasa, Surabaya: Erlangga. 1993.

[7] Handayani S, Istiqomah A, Fauzi N, Eva N. Increasing Young Entrepreneurs During the Covid-19 Pandemic Through Creative Economy Management. Jurkami: Jurnal Pendidikan Ekonomi. 2021; 6(1): 12-22.

[8] Kapoor H, Kaufman JC. Meaning-Making Through Creativity During Covid-19. Frontiers in Psychology. 2020; 11: 3659.

[9] Karwowski M, Zielińska A, Jankowska Dm, Strutyńska E, Omelańczuk I, Lebuda I. Creative Lockdown? A Daily Diary Study Of Creative Activity During Pandemics. Frontiers in Psychology. 2021; 12: 23.

[10] Sugihartini N, Agustini K, Pradnyana IMA. Video Editing Training for Vocational High Schools in Singaraja City. Widya Laksana. 2017; 6(2): 172-80.

[11] Nugroho IP. Understanding Teenage Curiosity Seen By Gender. Jurnal Bimbingan Dan Konseling Ar-Rahman. 2019; 5(1): 1-5.

[12] Suprapto S, Zubaidah S, Corebima Ad. The Effect of Gender on Students' Creative Thinking Skills in Biology Learning. Jurnal Pendidikan: Teori Penelitian, dan Pengembangan. 2018; 3(3): 325-9. 